\title{
CORRESPONDENCE
}

\section{Exposure at high altitude and exercise altered membrane diffusion capacity of the lung}

\section{To the Editors:}

In an article published in a recent issue of the European Respiratory Journal, DEHNERT et al. [1] report various measurements made after climbing at high altitude. Among them were carbon monoxide (CO) transfer measurements. I was surprised by the finding of an increase in the transfer factor of the lung for $\mathrm{CO}(T \mathrm{~L}, \mathrm{CO})$ at altitude, as an article presently in press [2], already published in abstract form [3], in which TL,CO and the transfer factor of the lung for nitric oxide $(T \mathrm{~L}, \mathrm{NO})$ decreased slightly but significantly at altitude. At 5,000 m, two thirds of the subjects decreased their $\mathrm{TL}, \mathrm{NO}$ by $>5 \%$ after a short maximal exercise. This discrepancy could be due to the fact that DEHNERT et al. [1] divided the measured value at altitude by a factor $<1$ which, in fact, should only be used to estimate the predicted values at altitude. Altitude hypoxia, due to reduced capillary oxygen pressure, increases the conductance of blood for $\mathrm{CO}$ and, therefore, the $\mathrm{CO}$ transfer. Thus, if one wants to compare the results obtained at altitude to those at sea level, we should either multiply the measured results by this factor or express the results as \% predicted, taking into account the equation cited in DEHNERT et al. [1] for the predicted value at altitude. When looking for a detection of interstitial oedema, NO transfer would be more sensitive than $\mathrm{CO}$, as the former is mainly dependent on the membrane conductance and the latter is dependent on both membrane and blood conductances [4].

\section{H. Guénard}

Physiologie et EFR, Université Bordeaux 2 et CHU, Bordeaux, France.

Correspondence: H. Guénard, Physiologie et EFR, Université Bordeaux 2 et CHU, rue Leo Saignat, Bordeaux, France. E-mail: herve.guenard@u-bordeaux2.fr

Statement of Interest: None declared.

\section{REFERENCES}

1 Dehnert C, Luks AM, Schendler G, et al. No evidence for interstitial lung oedema by extensive pulmonary function testing at $4,559 \mathrm{~m}$. Eur Respir J 2010; 35: 812-820.

2 De Bisschop C, Kiger L, Marden M, et al. Pulmonary capillary blood volume and membrane conductance in Andeans and lowlanders at high altitude: a cross-sectional study. Nitric Oxide 2010; [Epub ahead of print DOI: 10.1016/j.niox.2010.05.288].

3 De Bisschop C, Leurquin-Sterk G, Faoro V, et al. High altitude enhances exercise-induced lung diffusion alterations. Fundam Clin Pharmacol 2010; 24: Suppl. 1, 103.
4 Aguilaniu B, Maitre J, Glénet S, et al. European reference equations for CO and NO lung transfer. Eur Respir J 2008; 31: 1091-1097.

DOI: $10.1183 / 09031936.00053410$

From the authors:

H. Guénard points out a discrepancy of the transfer factor of the lung for carbon monoxide (TL,CO) measurements between data published in his group's abstract [1] and data we reported recently [2]. DE BISSCHOP et al. [1] observed a small but significant decrease in $T \mathrm{~L}, \mathrm{CO}$ in acclimatised subjects after maximal exercise at 5,000 m, which $\mathrm{H}$. Guénard considers to be in disagreement with the small increase we found in nonacclimatised subjects at rest at 4,559 m. He suggests that the discrepancy is due to an erroneous calculation of diffusing capacity of the lung for carbon monoxide $(D \mathrm{~L}, \mathrm{CO})$ on our part. Furthermore, he points out that transfer factor of the lung for nitric oxide (TL,NO), which was also slightly decreased in the study of DE BISSCHOP et al. [1], is a better measure of diffusion than TL,CO, since nitric oxide uptake is dependent only on membrane conductance and is not influenced by blood conductance.

First, we need to emphasise that corrections of the DL,CO measurements for altitude were done properly. The equipment used in the study performed an automated correction of DL,CO for the lower oxygen tension at altitude according to the formula given by MACINTYRE et al. [3]:

$$
D \mathrm{~L}, \mathrm{CO}, \mathrm{Alt}=\mathrm{DL}, \mathrm{CO} /\left(1+0.0031 \times\left(\mathrm{PI}_{\mathrm{I}} \mathrm{O}_{2}, \mathrm{Alt}-150\right)\right)
$$

where $D \mathrm{~L}, \mathrm{CO}$ and $D \mathrm{~L}, \mathrm{CO}, \mathrm{Alt}$ are the measured single-breath $D \mathrm{~L}, \mathrm{CO}$ at low altitude and that predicted for altitude, respectively, $\mathrm{PI}, \mathrm{O}_{2}$, Alt is the inspiratory oxygen tension $\left(\mathrm{PI}_{\mathrm{I}} \mathrm{O}_{2}\right)$ at altitude, and $150 \mathrm{mmHg}$ is the assumed at sea level.

As pointed out by $\mathrm{H}$. Guénard, this formula predicts $D \mathrm{~L}, \mathrm{CO}$ at high altitude based on measurements performed at low altitude. Since our values measured at high altitude were compared with the baseline values at low altitude, the automated correction multiplied the measured values by $\left(1+0.0031 \times\left(P \mathrm{I}, \mathrm{O}_{2}-150\right)\right)$, i.e. by a term that is less than one. In addition, data were corrected for changes in haemoglobin concentration according to the formula given by MACINTYRE et al. [3]. We apologise for not having explained these corrections in more detail.

One needs to consider that the diffusing capacity measurement, based as it is on gas diffusion at the alveolar level, is not 
very sensitive to any early interstitial oedema formation. The work of J.C. Parker and colleagues (reviewed in EFFros and PARKER [4]) shows that the alveolar capillary endothelium at rest has permeability only to hydrostatic stress of $\sim 5 \%$ compared with the larger upstream pulmonary artery endothelium. This means that the vast majority of fluid filtration of the lung vasculature occurs away from the alveolar capillary barrier. This notion is supported by only minor changes in $D \mathrm{~L}, \mathrm{CO}$ in subjects with radiographically evident high-altitude pulmonary oedema in our study [2].

The technique of measuring diffusing capacity of the lung for $\mathrm{NO}(\mathrm{DL}, \mathrm{NO})$ was not available at the time of the study. $\mathrm{H}$. Guénard suggests that we might have, therefore, missed evidence of interstitial oedema. This method is, however, not a perfect test for diffusion measurement either, because about of a third of $\mathrm{NO}$ uptake resistance is dependent upon the erythrocytes. Therefore, DL,NO is not just a reflection of changes in the alveolar capillary membrane [5] as $\mathrm{H}$. Guénard proposes.

We also want to point out that the level of acclimatisation and physical activity of subjects were very different between these two studies and, thus, preclude direct comparison. DE BISSCHOP et al. [1] examined subjects that had acclimatised over 1 week at an altitude of $5,000 \mathrm{~m}$ after maximal exercise, while we examined nonacclimatised subjects at rest (4,20 and $44 \mathrm{~h}$ after climbing) at 4,559 $\mathrm{m}$ [2]. Exercise at low [6] and high altitude [7] can cause mild interstitial oedema. Several studies suggest that a prolonged stay at high altitude may be associated with interstitial fluid accumulation in systemic tissues. This was shown for subcutaneous tissue [8] at 2,300 $\mathrm{m}$ and for mild pericardial effusion at 5,200 $\mathrm{m}$, which increased over the first 7 days [9]. Furthermore, a small decrease in lung compliance compatible with mild interstitial pulmonary oedema was measured by PELLEGRINO et al. [10] after 2 days of rest at 3,611 $\mathrm{m}$ and 1 day of rest at the same location, where we found no change in lung compliance during the first $48 \mathrm{~h}$ at altitude after more rapid ascent.

We thank H. Guénard for making us look again in detail at the published data, because we discovered that table 3 contained erroneous $D \mathrm{~L}, \mathrm{CO}$ values that had been corrected for altitude, in addition to the automated adjustment made by the computer of the body plethysmograph. We encountered problems with the submission of the large tables and were asked several times to repeat the uploading which, at one stage, lead to the submission of an old version of table 3 . We apologise for this error and for not detecting it when proof reading. We assure that the description and discussion of the data in the paper were correct. A corrected version of table 3 has been published in the current issue of the European Respiratory Journal, as part of an Author Correction that highlights and rectifies this mistake [11].

\section{Dehnert*, A.M. Luks", E.R. Swenson" ${ }^{\#}$ and P. Bärtsch*} *Internal Medicine VII, Sports Medicine, University Hospital Heidelberg, Heidelberg, Germany. "University of Washington, Division of Pulmonary and Critical Care Medicine, Seattle, WA, USA.

Correspondence: C. Dehnert, Internal Medicine VII, Sports Medicine, University Hospital Heidelberg, Im Neuenheimer, Heidelberg, D-69120, Germany. E-mail: christoph.dehnert@ med.uni-heidelberg.de

Statement of Interest: A statement of interest for this article can be found at www.erj.ersjournals.com $/ \mathrm{misc} /$ statements.dtl

Acknowledgements: We thank H-J. Smith (CareFusion GmbH, Hoechberg, Germany; formerly VIASYS Healthcare $\mathrm{GmbH}$ ) for his technical support.

\section{REFERNECES}

1 De Bisschop C, Leurquin-Sterk G, Faoro V, et al. High altitude enhances exercise-induced lung diffusion alterations. Fundam Clin Pharmacol 2010; 24: Suppl. 1, 103.

2 Dehnert C, Luks AM, Schendler G, et al. No evidence for interstitial lung oedema by extensive pulmonary function testing at 4,559 m. Eur Respir J 2010; 35: 812-820.

3 MacIntyre N, Crapo RO, Viegi G, et al. Standardisation of the single-breath determination of carbon monoxide uptake in the lung. Eur Respir J 2005; 26: 720-735.

4 Effros RM, Parker JC. Pulmonary vascular heterogeneity and the Starling hypothesis. Microvasc Res 2009; 78: 71-77.

5 Borland CD, Dunningham H, Bottrill F, et al. Significant blood resistance to nitric oxide transfer in the lung. J Appl Physiol 2010; 108: 1052-1060.

6 Hopkins SR, Schoene RB, Henderson WR, et al. Sustained submaximal exercise does not alter the integrity of the lung blood-gas barrier in elite athletes. J Appl Physiol 1998; 84: 1185-1189.

7 Anholm JD, Milne EN, Stark P, et al. Radiographic evidence of interstitial pulmonary edema after exercise at altitude. J Appl Physiol 1999; 86: 503-509.

8 Gunga HC, Kirsch K, Baartz F, et al. Fluid distribution and tissue thickness changes in 29 men during 1 week at moderate altitude (2,315 m). Eur J Appl Physiol Occup Physiol 1995; 70: 1-5.

9 Thompson AA, Baillie JK, Toshner M, et al. Pericardial effusions in healthy lowlanders after acute ascent to high altitude. Heart 2006; 92: 539-540.

10 Pellegrino R, Pompilio P, Quaranta M, et al. Airway responses to methacholine and exercise at high altitude in healthy lowlanders. J Appl Physiol 2010; 108: 256-265.

11 Dehnert C, Luks AM, Schendler G, et al. Author Correction: No evidence for interstitial lung oedema by extensive pulmonary function testing at 4,559 m. Eur Respir J 2010; 36: 699.

DOI: $10.1183 / 09031936.00092610$ 